\title{
Release of Medicago truncatula Gaertn. and Pisum sativum subsp. elatius (M. Bieb.) Asch. et Graebn. Seed Dormancy Tested in Soil Conditions
}

\author{
Juan Pablo Renzi ${ }^{1}$, Jan Brus ${ }^{2} \oplus$, Stergios Pirintsos ${ }^{3}$, László Erdós ${ }^{4,5}$, Martin Duchoslav ${ }^{6} \mathbb{C}$ \\ and Petr Smýkal 6,*iD \\ 1 Instituto Nacional de Tecnología Agropecuaria, Hilario Ascasubi 8142, Argentina; \\ renzipugni.juan@inta.gob.ar \\ 2 Department of Geoinformatics, Palacký University in Olomouc, 17. listopadu 50, 77146 Olomouc, \\ Czech Republic; jan.brus@upol.cz \\ 3 Department of Biology and Botanical Garden, University of Crete, 71409 Heraklion, Greece; pirintsos@uoc.gr \\ 4 Institute of Ecology and Botany, MTA Centre for Ecological Research, H-2163 Vácrátót, Hungary; \\ erdos.laszlo@okologia.mta.hu \\ 5 MTA-DE Lendület Functional and Restoration Ecology Research Group, H-4028 Debrecen, Hungary \\ 6 Department of Botany, Palacký University in Olomouc, Šlechtitelů 27, 78371 Olomouc, Czech Republic; \\ martin.duchoslav@upol.cz \\ * Correspondence: petr.smykal@upol.cz; Tel.: +420-585-634-827
}

Received: 1 June 2020; Accepted: 12 July 2020; Published: 16 July 2020

check for updates

\begin{abstract}
Medicago truncatula (barrel medic) and Pisum sativum subsp. elatius (wild pea) accessions originating from variable environmental conditions in the Mediterranean basin were used to study physical seed dormancy (PY) release. The effect of soil burial on PY release was tested on 112 accessions of medic and 46 accessions of pea over the period of 3 months in situ at three common gardens (Hungary, Spain and Greece) from 2017 through 2019. PY release after soil exhumation followed by experimental laboratory germination of remaining dormant seeds (wet, $25^{\circ} \mathrm{C}, 21$ days) were related to the environmental conditions of the common garden and macroclimatic variables of the site of origin of the accessions. Higher PY release was observed in buried seeds under humid rather than under dry and hot environments. Exposure of remaining dormant seeds to experimental laboratory conditions increased total PY release up to $70 \%$ and $80 \%$ in barrel medic and wild pea, respectively. Wild pea showed higher phenotypic plasticity on PY release than barrel medic, which had higher bet-hedging within-season. Wild pea showed lower bet-hedging among-season ( $\mathrm{PY}<10 \%)$ in relation to precipitation than barrel medic, which was more conservative ( $P Y \approx 20 \%$ ). Observed variability suggests that these species have the capability to cope with ongoing climate change.
\end{abstract}

Keywords: bet-hedging; germination; Medicago; pea; plasticity; seed dormancy; soil seed bank

\section{Introduction}

Seeds represent a critical stage in the life cycle of plants because they ensure dispersal and recruitment of new seedlings. Seedling emergence is an especially vulnerable window affecting population and community dynamics [1]. Germination timing impacts survival by regulating when to release a vulnerable embryo, which was previously protected inside of the seed, into a variable and often unpredictable environment. Various blocks to seed germination (seed dormancy) have evolved in order to control this process [2,3]. The most studied is physiological dormancy using the Arabidopsis model [4,5], while release from physical dormancy (PY) is less understood. Physical dormancy is 
frequent in legumes, where it is controlled by an impermeable seed coat [6], and commonly found in species occurring in arid and semi-arid regions [2,7].

Environmental variance has both a predictable and stochastic character [8]. Phenotypic plasticity $[9,10]$ and bet-hedging [11] are two principal classes of adaptation to environmental change: each can alter the range of phenotypes expressed in a population as the environment changes [12].

Phenotypic plasticity of seed germination occurs only when environmental cues are perceived by seeds, and if these cues reliably predict germination conditions that lead to successful establishment $[10,13]$. Phenotypic plasticity is thus mostly expected when changes in environmental conditions are at least partially predictable within an organism's lifespan. Consequently, plasticity maximizes fitness across environments [14]. In unpredictable environments where temporal variation is high, however, the imperfect control of germination timing may account for negative population growth, and in extreme cases a population may die out in a year with unsuitable conditions. Long-term fitness variance may be reduced by avoiding risky investments (conservative or among season bet-hedging strategy) or, alternatively, by spreading risk among offspring (diversified or within season bet-hedging strategy) $[11,15,16]$. Concerning germination, the bet-hedging strategy acts to spread establishment risk for the seed produced by an individual plant by spreading germination across the growing season or among several years. A strategy in which only a fraction of seeds germinates, leaving the remaining seeds alive and dormant, tends to maximize fitness in environments where the probability of successful growth is low and varies at random [11]. This reduces short-term reproductive success in favor of longer-term risk reduction [15].

Dormancy release and timing of germination is a trait in which the evolution of both phenotypic plasticity and bet-hedging is expected [8], especially under partially predictable conditions [17]. The proportion of dormant seeds and dormancy releasing environmental cues are known to vary between and among individuals of given species [18], resulting in different seasonal patterns of germination. Breaking of PY in natural conditions is proposed to be caused by the softening of the seed coat, mediated through alternating temperatures [19-24], which are typical in soils of Mediterranean and sub-tropical climates $[2,25,26]$. Such climates with seasonality seem to evolutionarily select for seed dormancy [7] as shown by Rubio de Casas et al. [27]. Therefore, seed dormancy is likely the major driver of species distribution as seeds must first be able to germinate in a habitat in order for post-germination traits (including flowering and seed set) to occur [28].

Barrel medic (Medicago truncatula) is a representative species adapted to a Mediterranean climate characterized by strong seasonality with hot and dry summers often with large diurnal temperature oscillations followed by main rainfall in the autumn-winter [29]. Likewise, Pisum sativum subsp. elatius (wild pea) offers an excellent model to study legume seed physical dormancy in an ecological context [30] due to its wide-ranging native distribution, spanning from the western Mediterranean, through south-eastern Europe to the Middle East [31,32]. We have previously analyzed variation in dormancy release of Pisum sativum subsp. elatius [30] and M. truncatula [33] seeds to temperature alternations, tested in water-saturated conditions in the laboratory. Barrel medic seed dormancy release plasticity correlated with increased aridity of the environment of origin, suggesting that plastic responses provide seeds with a bet-hedging capacity [33]. In wild pea, dormant genotypes are found in the environment with smaller temperature variation, seasonality and milder winter. Genotypes responsive to temperature oscillations originate from environments with lower annual temperatures, colder winters and higher temperature fluctuations [30]. However, there is scarce knowledge about the degree of PY variability, both among and within accessions, under natural soil conditions, where both temperature and moisture conditions vary in a complex manner [34,35]. Given the limited knowledge on the regulation of legume seed dormancy under natural conditions [6], this study addresses the gap in knowledge on the association between the PY release and environmental factors using experimental burial of seeds of accessions of both legume species originating from various climatic environments into natural soils of three common gardens covering climatic conditions within the ranges of both studied species. After the exposition of seeds to natural soil, the remaining seeds were excavated and non-germinated seeds were tested in the laboratory for dormancy release. 
The following questions were addressed. (1) What is the physical seed dormancy release pattern among accessions in barrel medic and wild pea under soil seed burial environments? (2) How much difference is there between seed dormancy release under laboratory conditions and soil burial environment? (3) What is the dormancy release strategy potentially driving adaptation among accessions of barrel medic and wild pea originating from different climatic conditions?

\section{Materials and Methods}

\subsection{Plant Material}

Corresponding to the study by Renzi et al. [33], a set of 112 M. truncatula accessions originated from INRA Montpellier (http://www1.montpellier.inra.fr) and from the University of Minnesota, USA (http://www.medicagohapmap.org). Forty-six wild pea (Pisum sativum subsp. elatius) accessions were selected from previous studies [30,31]. Accessions of both studied species were selected with the aim to cover geographical species range and diverse ecological conditions.

To obtain sufficient seed stock for the experiments and to minimize environmentally induced maternal effects, obtained seeds were planted and cultivated in glasshouse conditions at the Department of Botany, Palacký University, Olomouc, Czechia from September to May $(2017,2018$, and 2019) in either 3 litre (barrel medic) or 5 litre (wild pea) pots with sand peat substrate (1:9) mixture (Florcom Profi, BB Com Ltd., Letovice, Czechia), watered daily and fertilized weekly (Kristalon Plod a Květ, Agro Ltd., Říkov, Czechia). Supplementary light (Sylvania Grolux 600 W, Hortilux Schreder, Holland) was provided to extend the photoperiod to $14 \mathrm{~h}$. The mature pods were collected, packed in paper bags, dried at room temperature $\left(22-24^{\circ} \mathrm{C}\right), 30 \%$ air humidity and seeds were manually cleaned $[30,31,33]$. After that, the randomly selected seeds of each accession were packed into permeable nylon bags within 2 to 3 weeks from the harvest and prepared for soil burial experiments. During the 2016, 2017 and 2018 periods, at the onset of the summer season, batches of 50 seeds were placed inside permeable nylon mesh bags (mesh size $=200 \mu \mathrm{m}$, KD Filter, Ústí nad Labem, Czechia). A portion of the same seed batches was tested in laboratory conditions as previously $[30,31,33]$.

\subsection{Soil Deposition Experiment}

Three common garden sites (locations) for the soil burial experiment covered climatic conditions within the ranges of both studied species: Cordoba, southern Spain (SPN) $(37.858933,-4.800390$, $180 \mathrm{~m}$ a.s.1.), Panormo, Crete, Greece (GRC) (35.4174721, 24.6829471, $132 \mathrm{~m}$ ) and Villany, southern Hungary (HUN) $(45.8652763,18.4455547,133 \mathrm{~m})$. The two former locations corresponded to arid summer soil environments (SPN and GRC) and the later one to humid soil conditions (HUN) (Table S1 and Figure S1). Bags (one per accession and site) with seeds were buried in an open place of each location into the soil at $5 \mathrm{~cm}$ depth, covered with a wire cage to prevent predation, and were exposed from about 15 June (start of the experiment) until the end of September repeatedly in 2017, 2018 and 2019. Thereafter the bags were excavated and within 2 days shipped to the laboratory at Palacky University, Olomouc, Czechia. Here the bags with seeds were opened and seeds were classified into three categories depending of their dormancy status: those that germinated in situ, those that imbibed in situ, and those that were considered dormant in situ. The proportion of buried seeds ( $n=50$ per each bag) that either germinated or imbibed in situ was called "PY release soil". In situ dormant seeds were immediately transported (within $24 \mathrm{~h}$ of excavation, in paper boxes) to the laboratory, placed onto wet filter paper in Petri dish and subjected to $25^{\circ} \mathrm{C}$, in the dark under laboratory conditions. This temperature was selected based on our previous experiments $[30,31,33]$ in order not to introduce further temperature variables beside the one experienced during burial. In order to prevent fungal growth (as seeds sterilization would alter seed coat properties), fungicide Maxim XL $035 \mathrm{FS}$ (containing metalaxyl $10 \mathrm{~g}$ and fludioxonil $25 \mathrm{~g}$ ) was applied. Seeds were monitored at $24 \mathrm{~h}$ intervals for a total of 21 days. At the end of the testing period, all germinated and imbibed seeds in 
both in situ (soil) and laboratory conditions were counted and expressed as the proportion of the total

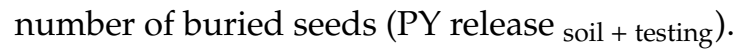

\subsection{Meteorological and Environmental Data Acquisition}

The WorldClim (http://worldclim.org) version 2.0 database was used to extract information about the climate (period 1970-2000) for each site of accession's origin in both species [36]. Data were extracted using DIVA-GIS software from ESRI grids with a spatial resolution of 30 arc-seconds $(\sim 1 \mathrm{~km})$ in the WGS-84 (EPSG: 4326). The meteorological data for common garden sites (locations) were obtained using the Weather Underground service. Weather Underground uses professional stations and observations from members with automated personal weather stations (PWS). Weather Underground's WunderMap overlays weather data from personal weather stations and official NWS stations on a Mapbox Map base and provides many interactive and dynamically updated weather and environmental layers. The service also provides historical data. For data analysis, we selected daily data for the selected time period for years 2017, 2018 and 2019. We downloaded temperature data (high, low and average) and the daily sum of precipitation accumulation $(\mathrm{mm})$ data. For the soil burial experiment, the closest weather station to each common garden was selected with the aim of obtaining the best available local data. Where the topography conditions influenced the weather, we tried to select a most similar but not closest station. Consequently, we selected the following climatic stations: Córdoba, Spain (ICRDOBAC5), Szarsomlyo, Hungary (IBARANYA11) and Pantánassa, Crete (IU039AU07) (see Table S1 for details).

\subsection{Data Analysis}

\subsubsection{PY Release of Barrel Medic and Wild Pea Accessions in Natural Soil Condition}

To test if the accessions differed in the proportion of PY release, a linear mixed model (LMM) was performed using the accessions and localities as fixed factors and year as a random factor nested within a locality. One hundred and twelve barrel medic accessions (Table S2) and 46 wild pea accessions were evaluated (Table S3). The LMM was performed with R version 3.6.1 (R Development Core Team 2019) using the packages MASS, nlme and GLM in Infostat [37] and its interface to R (R 3.6.1, R Development Core Team 2019), using a significance threshold of $p<0.05$. For analyses, the PY data were arcsin-square root transformed, and the untransformed data are presented in the Figures for clarity. The PY release mean of each environment was plotted as a function of local climatic condition, ( 3 locations $\times 3$ years, excluding Greece in 2019, in which the seeds did not arrive on the proper date to be buried), of the respective environment (mean daily temperature $\left({ }^{\circ} \mathrm{C}\right)$, degrees day $\left({ }^{\circ} \mathrm{Cd}\right)$ and precipitation $\left(\mathrm{n}^{\circ}\right.$ of events and $\mathrm{mm}$ )) during burial trial (15 June to 30 September). Degree days were the sum of the mean daily temperature (threshold temperature $=0{ }^{\circ} \mathrm{C}$ ) for the duration of the soil deposition experiment for each year. A linear regression analysis was performed using GraphPad Prism Software version 6.0 (GraphPad, San Diego, California, USA). Pearson's correlation coefficient was calculated between the environmental variable of the site of origin in each accession, in both species, and the proportion of PY release soil + testing using the InfoStat software (Tables S4 and S5).

\subsubsection{Association between PY Release under Laboratory Condition and Soil Burial Environment}

The data generated in this study were contrasted to the previous results of dormancy release tests under laboratory conditions for wild pea and barrel medic [31,34] (Tables S2 and S3). For each accession of barrel medic and wild pea with available data from both previous and present experiments, Pearson's correlation coefficient was calculated between the final PY release separately for each temperature treatments (alternating temperatures of $35 / 15^{\circ} \mathrm{C}$ and $25 / 15^{\circ} \mathrm{C}$ in a $14 \mathrm{~h} / 10 \mathrm{~h}$ regime onto water-saturated filter papers) during one month in laboratory $v s$ the PY release under soil conditions of the present study. 


\subsubsection{Relationship between Environment of Origin and PY Release under in Situ (Soil) Condition}

The barrel medic and wild pea accessions were grouped into four environmental clusters to improve ecological interpretation between the environment of origin and the PY release of each accession in common gardens. Several bioclimatic variables related to aptitude for seedling survival during summer and growth performance during the autumn-winter were selected [34]. In addition, to avoid over-parameterization among the bioclimatic variables, Pearson correlation coefficients were used to measure pairwise correlations among the variables ( $R$, Version 3.5.1); one of the two paired variables with $r>0.7$ was eliminated (Table S4). The bioclimatic variables were selected to represent summer and winter trends and extreme conditions of temperature and precipitation. The matrix of reduced-set of WordClim variables (maximum temperature of the warmest month (BIO5), mean temperature of warmest quarter (BIO10), annual precipitation (BIO12), precipitation of wettest quarter (BIO16), and precipitation of warmest quarter (BIO18)) [36] was analysed by principal component analysis (PCA) using Infostat software [37]. Accessions were grouped into four macroclimatic clusters based on Euclidean distance of environmental variables used for calculations of PCA [38]. Agglomeration was performed using Ward's minimum-variance linkage algorithm.

Four environmental clusters resulted: (i) Dry-dry (red): corresponds to accessions originating from dry conditions (high temperature and low rainfall) both during the dormancy release (summer) and growth (autumn-winter); (ii) Dry-humid (green): corresponds to accessions originating from dry conditions (high temperature and low rainfall) during the dormancy release but humid conditions during the growth season; (iii) Humid-dry (yellow): corresponds to accessions originating from humid conditions (medium temperature and high rainfall) during the dormancy release but dry conditions during the growing season; and (iv) Humid-humid (blue): corresponds to accessions originating from humid conditions (medium temperature and high rainfall) both during the dormancy release and during the growing season.

In all cases, reaction norms for each macroclimatic cluster were estimated as follows: each regression line represents mean PY release soil of the accessions of the respective macroclimatic cluster to the effect of soil moisture condition ( $\mathrm{n}^{\circ}$ of events and total precipitation) of each environment (combinations of common garden location and year of seed burial experiment) [39]. Precipitation was chosen because it was the main triggering factor for PY dormancy release (see Section 3.1). In order to focus on the change of the trait (slope and proportion of PY) in response to soil condition the PY dormancy means between each cluster were analyzed by ANOVA, and were compared by Fisher's least significant difference test using the InfoStat software [37].

\section{Results}

\subsection{PY Release of Barrel Medic and Wild Pea Accessions in Natural Soil Condition}

PY release soil between accessions ranged from 18 to $82 \%$ with mean $44 \%(S D=11)$ in barrel medic, and from 7 to $96 \%$ with mean $24 \%$ (SD = 14) in wild pea, considering all localities. After testing under controlled conditions, mean PY release soil + testing increased to $69 \%(\mathrm{SD}=13)$ in barrel medic (Figure 1), and to $79 \%(\mathrm{SD}=12)$ in wild pea (Figure 2), respectively. In the studied species, PY release soil + testing was significantly higher than PY release soil (Figure S2).

In both species HUN location showed a trend of higher PY release soil (Figure 3), associated with more mesic conditions than SPN and GRC (Table S1, Figure S1). In barrel medic, the frequency of rainfall events was associated with PY release soil more than the total $(\mathrm{mm})$, unlike wild pea that showed significant positive relationships with both environmental variables (Figure 4). In both species, lower mean temperature and degree days were associated with PY release (Figure 4). 
-10il $\quad F_{102,310}=1.5, \mathrm{P}<0.001$
soil + testing $\quad F_{102,310}=2.5, \mathrm{P}<0.001$

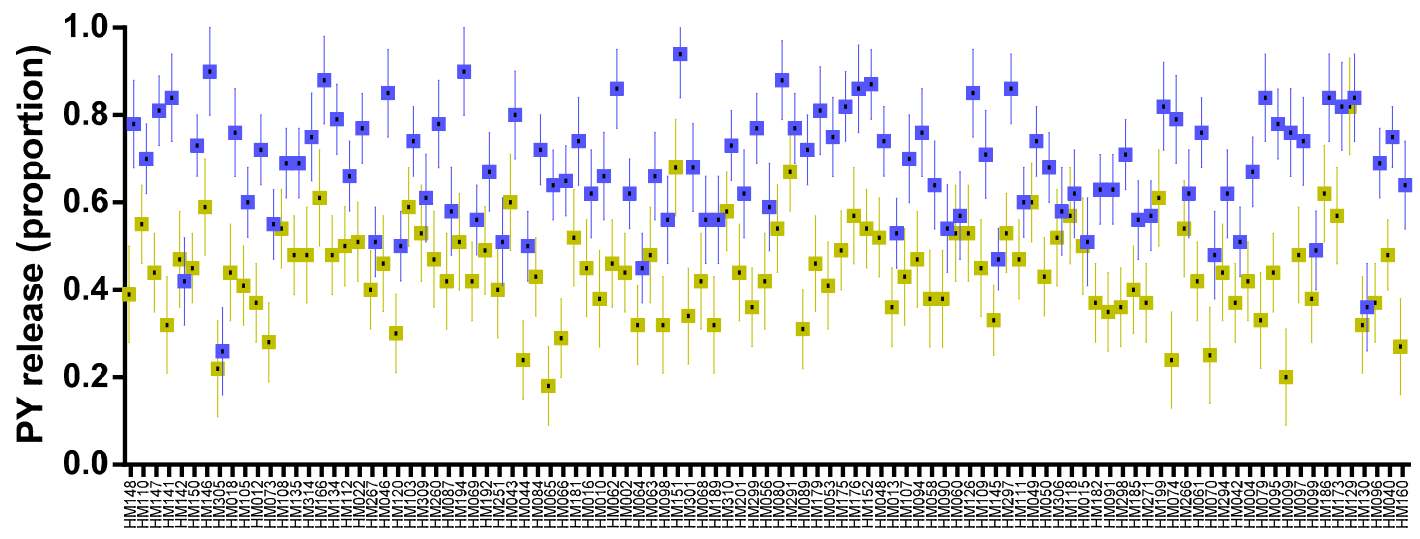

$(-)$

Annual precipitation (BIO12)

$(+)$

Figure 1. Proportion (mean $\pm \mathrm{sd}$ ) of PY release of M. truncatula accessions after soil exhumation (soil) and after laboratory testing condition $\left(25 / 15^{\circ} \mathrm{C}, 21\right.$ days) (soil + testing). Mean of each accessions in all environments are ordered according to the annual precipitation (BIO12) gradient of the accessions origin, with HM148 being from the driest (154 $\mathrm{mm}_{\text {year }}{ }^{-1}$ ) and HM298, from the wettest (1028 mm year $^{-1}$ ) conditions.
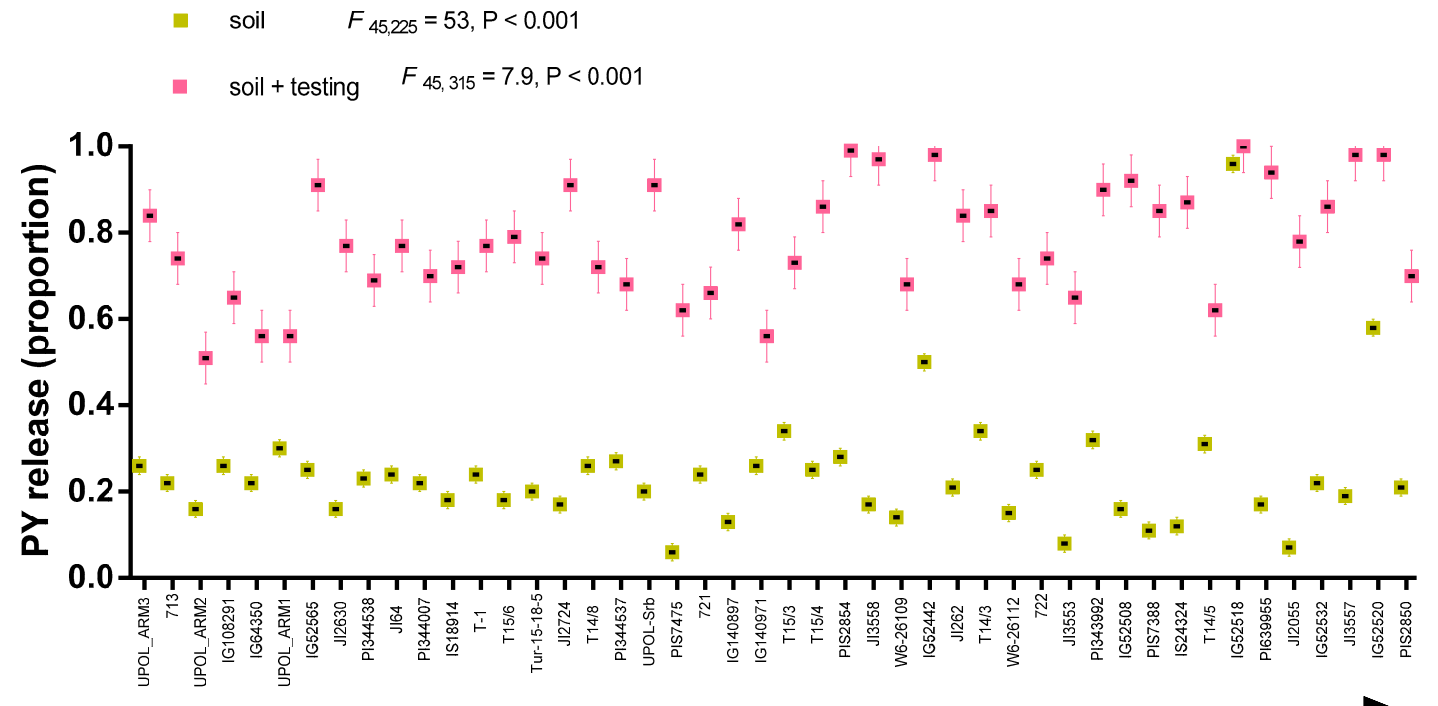

$(-)$

Annual precipitation (BIO12)

$(+)$

Figure 2. Proportion (mean $\pm \mathrm{sd}$ ) of PY release of Pisum sativum subsp. elatius accessions after soil exhumation (soil) and after laboratory testing condition $\left(25 / 15^{\circ} \mathrm{C} 21\right.$ days) (soil + testing). Mean of each accessions in all environments are ordered according to the annual precipitation (BIO12) gradient, with UPOL_ARM3 being from the driest (270 mm year ${ }^{-1}$ ) and PIS2850, from the wettest (1281 mm year $^{-1}$ ) conditions. 

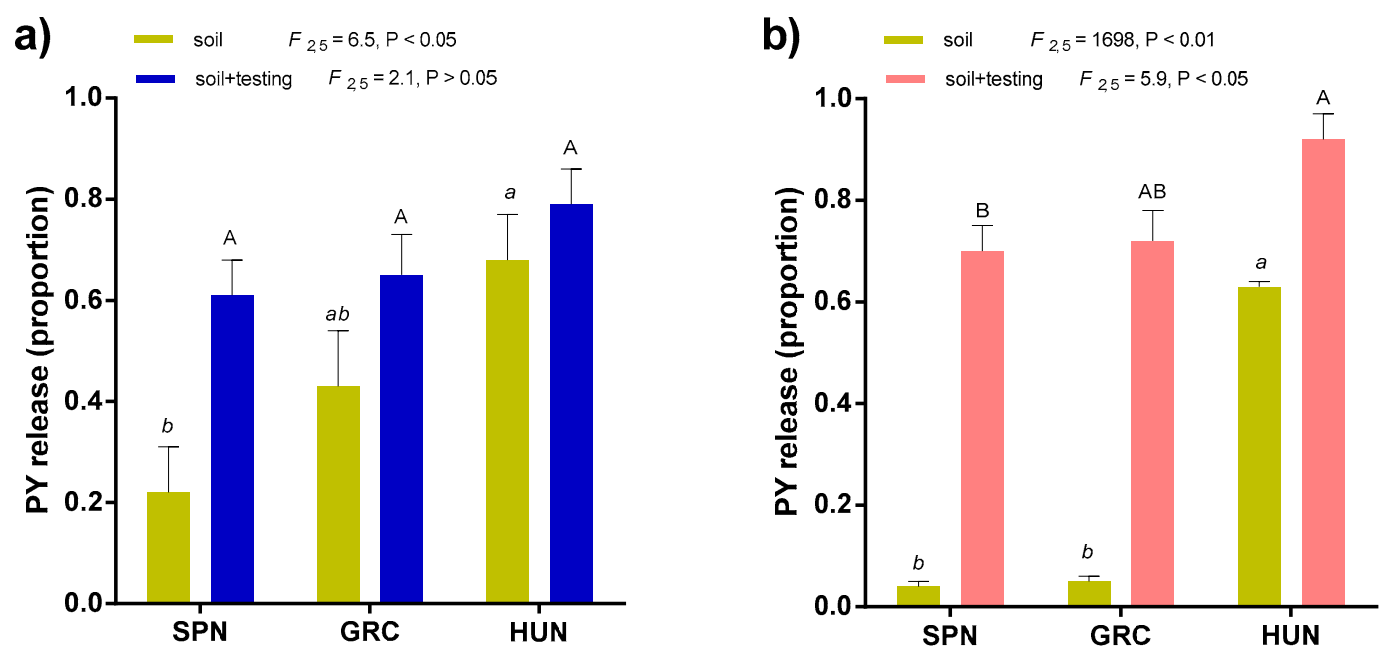

Figure 3. Proportion (mean $\pm \mathrm{sd}$ ) of PY release in each locality of M. truncatula (a) and Pisum sativum subsp. elatius (b) after soil exhumation (soil) and after laboratory condition ( $25 / 15{ }^{\circ} \mathrm{C} 21$ days) (soil + testing). HUN = Hungary, SPN = Spain, and GRC = Greece. Small letters and capital letters indicate significantly different means with respect to PY release after soil exhumation (soil) and soil + laboratory testing conditions, respectively (Fisher's LSD test, $\alpha=0.05$ ).
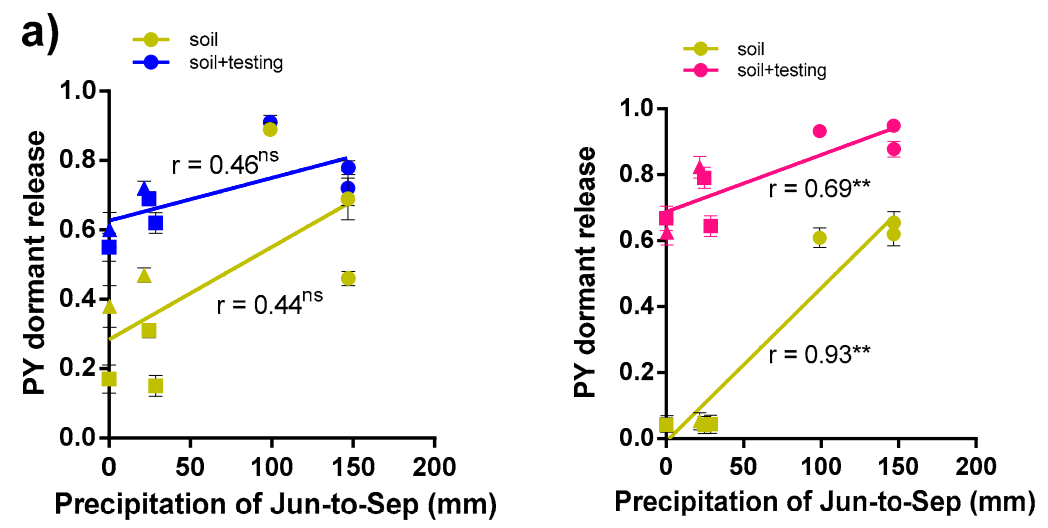

b)
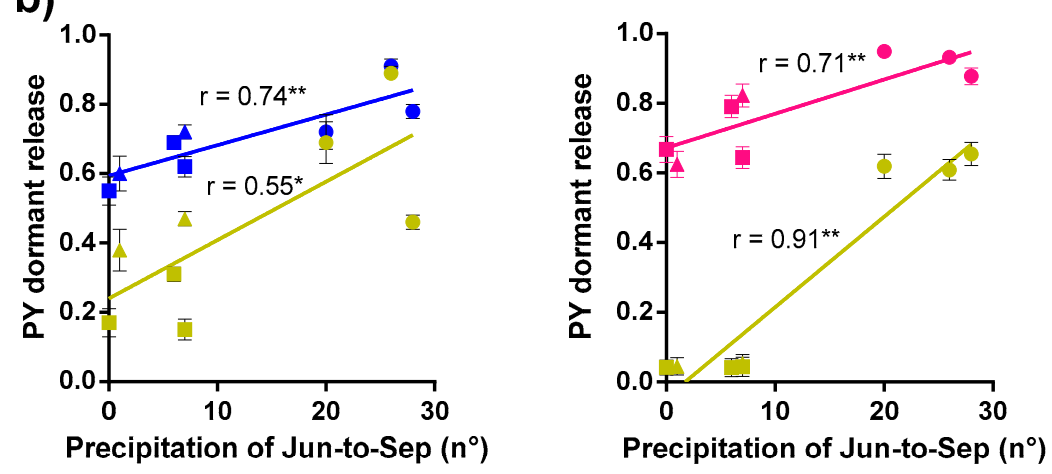

Figure 4. Cont. 

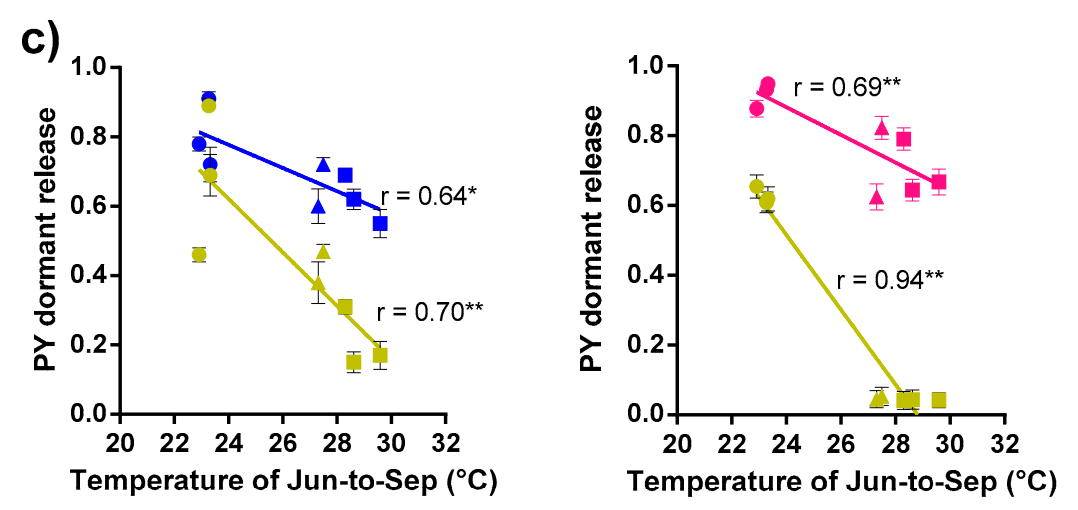

d)
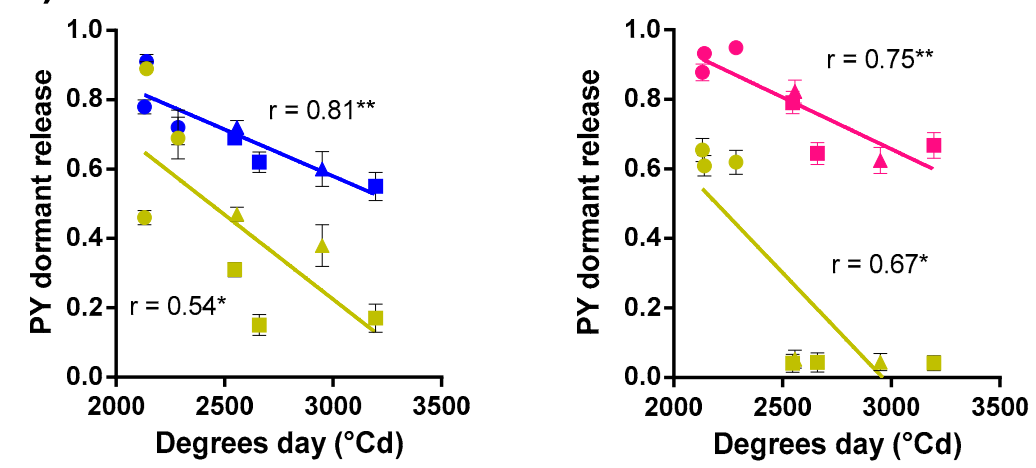

Figure 4. Regressions of the proportion of PY release in barrel medic (left) and wild pea (right) seeds and precipitation (a), frequency of precipitation (b), temperature (c), and degrees day (d) during burial periods of each common garden in three years. Symbols HUN (circle), SPN (square) and GRC (triangle).

'**' Indicates significance at $p<0.01$ and '*' at $p<0.05$. 'ns', not significant.

\subsection{Correlations between PY Release under Laboratory Condition and Soil Burial Environment}

There were positive correlations between PY release tested both under soil condition (present paper; PY release soil) and the experimental testing in laboratory $\left(25 / 15^{\circ} \mathrm{C}\right.$ and $35 / 15^{\circ} \mathrm{C}$ oscillating temperatures $[30,33]$. Laboratory conditions at $25 / 15{ }^{\circ} \mathrm{C}$ oscillating temperatures were better in predicting the behavior of PY release soil than those at $35 / 15^{\circ} \mathrm{C}$ oscillating temperatures in both species (Tables S5 and S6).

\subsection{Relationship between Environment of Origin and PY Dormancy Release Under Soil Conditions}

Pearson correlations between PY release and eco-climatic conditions of the accession origin in barrel medic was variable between the environments (common garden location $\mathrm{x}$ year). In contrast to the lack of association in an arid environment (soil), there was a significant positive correlation between PY release (both soil and soil + testing) and temperature seasonality (BIO 4) of the accession's origin under humid soil environment (Table S7). PY release of wild pea accessions were related more to the eco-climatic conditions of the site of accession's origin, and higher PY release was associated with higher temperatures of the warmest quarter (soil; $\mathrm{BIO} 5$ and BIO10) and precipitation during the growing season (soil + testing; BIO16 and 19) (Table S8).

The PCA of reduced WorldClim data set (Figures 5 and 6) revealed four clusters in relation to the macroclimatic conditions of sites of accession's origin, differing predominantly by summer and autumn-winter time conditions. PC1 explained 56.2\% (barrel medic) and 59.8\% (wild pea) of the total variation and can be interpreted as a gradient of summer aridity. PC2 explained $34.6 \%$ (barrel medic) and $22.9 \%$ (wild pea) of the total variation, and can be interpreted as a gradient of winter aridity. The dry-dry cluster corresponded to the most restrictive condition for the survival and growth of plants. This cluster contained the largest number of accessions, with $54 \%$ in medic and $41 \%$ in wild 
pea, respectively (Figure 5). The extent of PY release soil change (slope of regression line) in response to soil moisture condition ( $\mathrm{n}^{\circ}$ of events and total precipitation) showed the phenotypic plasticity, and this was higher in wild pea in relation to barrel medic $\left(F_{1147}=57.7, p<0.0001\right)$, although no differences in slopes of regression lines were found among clusters within each species (Figure 7). The residual variance around the linear regression in the case of wild pea was lower than in barrel medic (Figure 7).
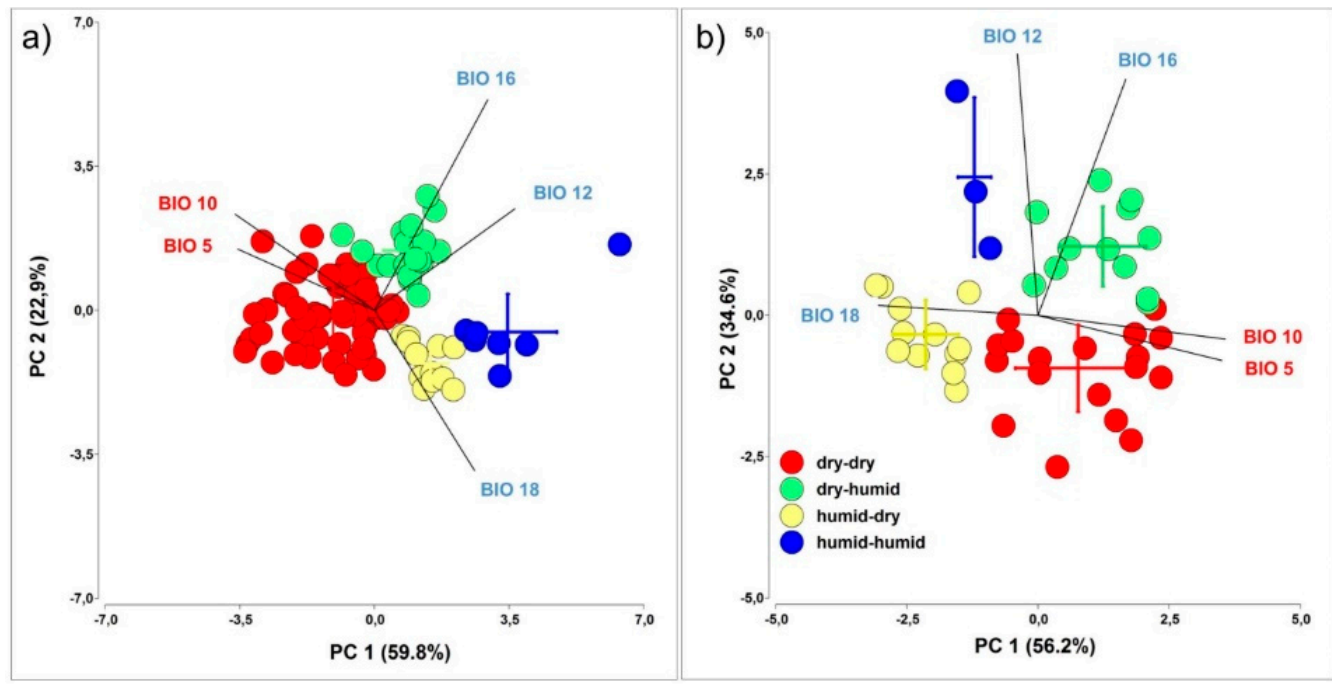

Figure 5. Principal component analyses (PCA) of selected bioclimatic variables of sites of origin of barrel medic (a) and wild pea accessions (b). Four different macroclimatic clusters were defined and visualised in the diagrams, based on the cluster analysis of Wordclim data (see Section 2.4.3).

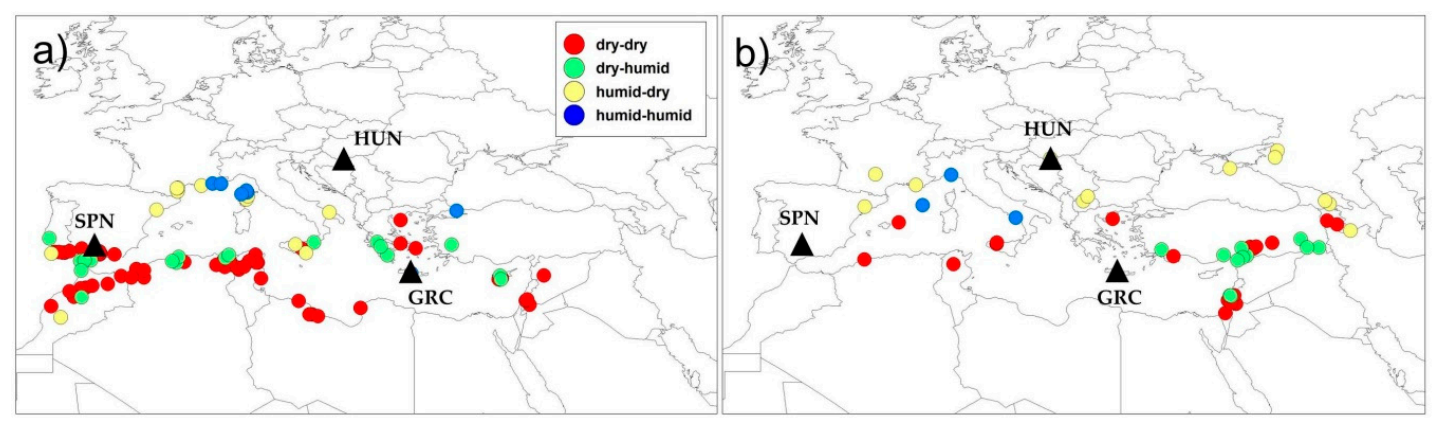

Figure 6. Geographic distribution of studied barrel medic (a) and wild pea (b) accessions classified in four clusters based on selected bioclimatic variables of sites of origin using Ward's minimum-variance linkage of Euclidean distance. The black triangles show soil burial locations.

PY release means between each cluster in barrel medic showed no significant difference (PY ${ }_{\text {soil }}$,

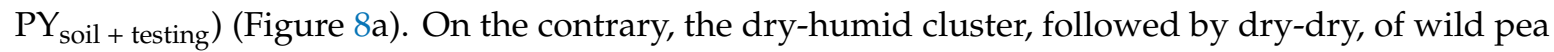
had a higher proportion of seeds ready to germinate than the rest of the clusters under common garden (Figure 8b). While barrel medic showed higher PY release after soil exhumation than wild pea $\left(F_{1786}=62.8, p<0.0001\right)$, total dormancy release was higher in wild pea than barrel medic because more in situ ungerminated seeds of wild pea imbibed under laboratory conditions $\left(F_{1786}=19.9\right.$, $p<0.0001$ ) (Figure 8). 

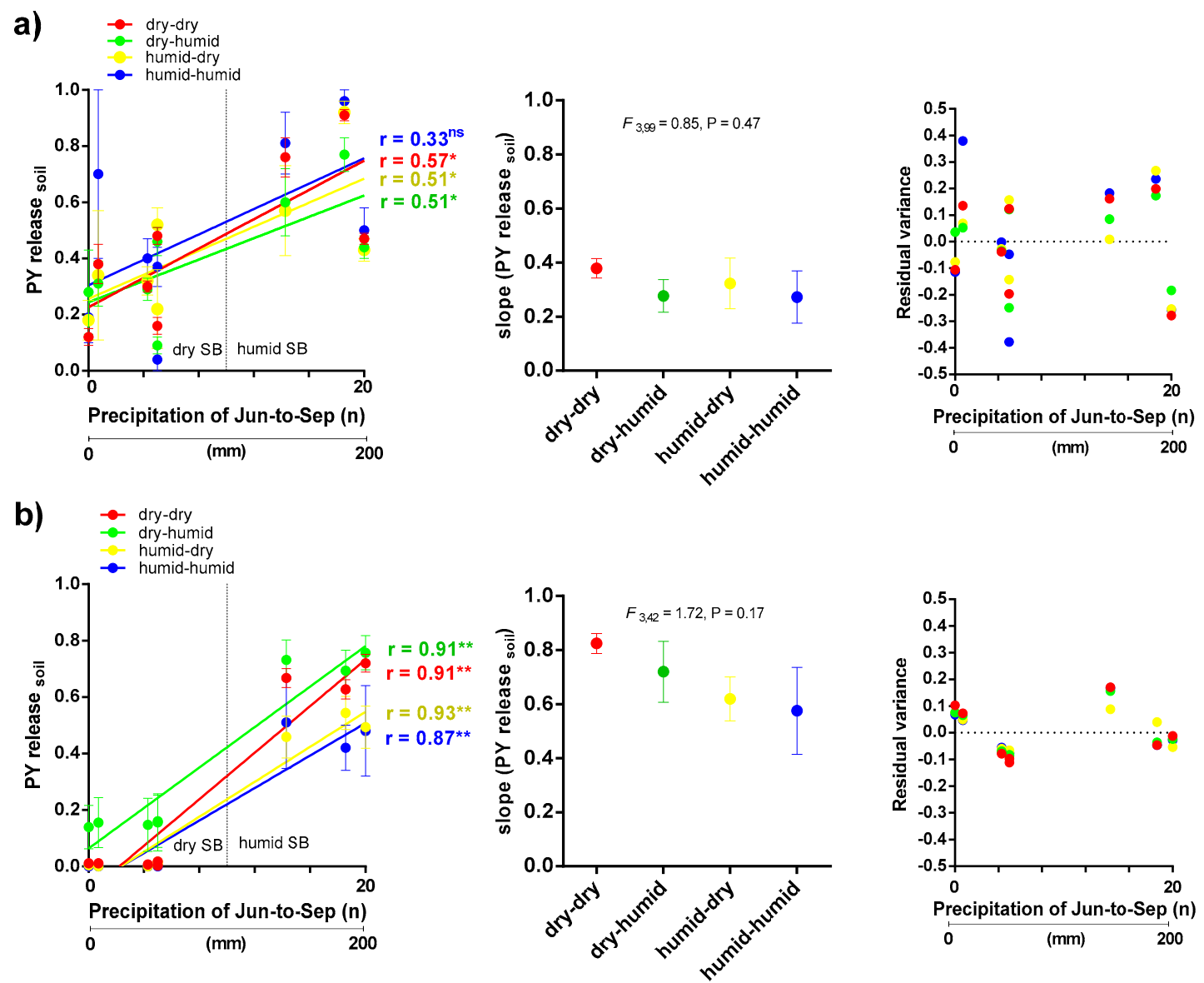

Figure 7. Norms of reaction, slopes (representing phenotypic variation), and residual variances (representing amount of bet-hedging) of PY release soil in accessions of barrel medic (a) and wild pea (b) in response to precipitation at common garden sites over three years. Red, green, yellow and blue lines correspond to dry-dry, dry-humid, humid-dry and humid-humid conditions of the macroclimate, respectively. "**' Indicates significance at $p<0.01$ and '*' at $p<0.05$. 'ns', not significant.

a)
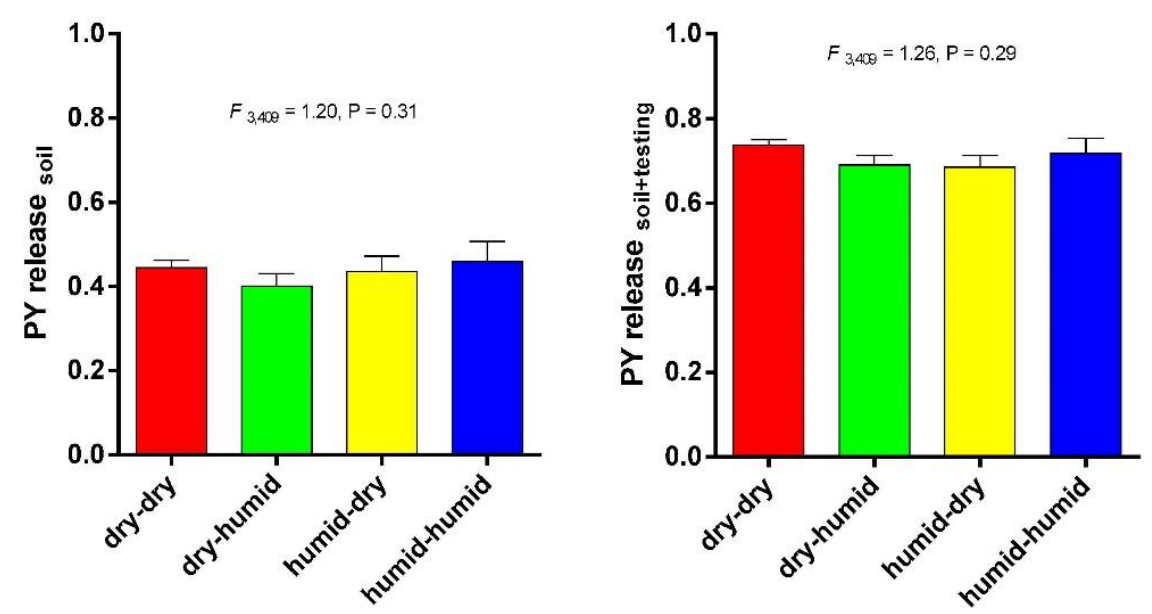

Figure 8. Cont. 
b)

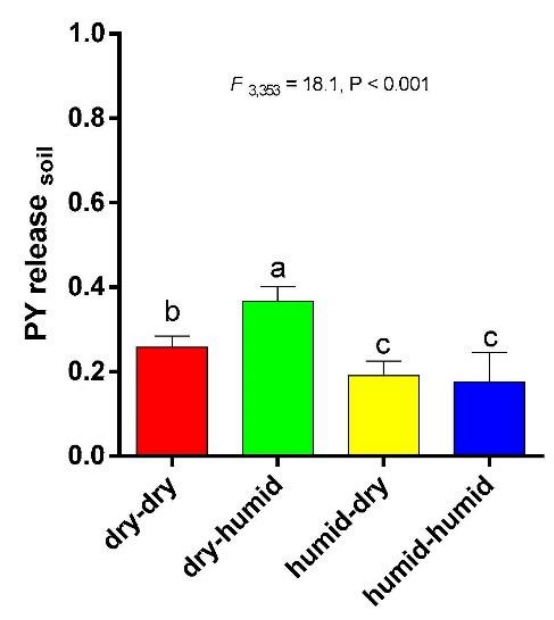

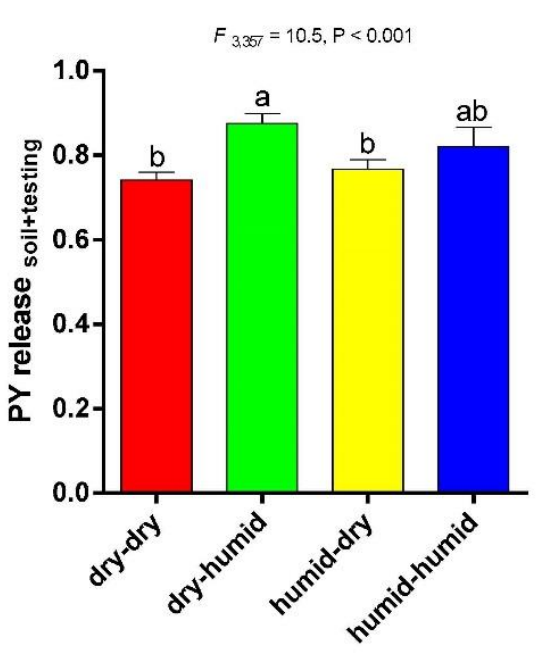

Figure 8. PY release after soil exhumation (PY release soil, left) and after testing (PY release soil + testing, right) in barrel medic (a) and wild pea (b) clustered by macroclimatic conditions at accessions' origin. Vertical bars indicate \pm s.e.m. Small letters indicate significantly different means with respect to macroclimatic clusters (Fisher's LSD test, $\alpha=0.05$ ).

\section{Discussion}

\subsection{Association between PY Release under Laboratory Conditions and Soil Burial Environment}

Patterns of germination may reflect local adaptation [2]. This has been typically tested by either common gardens or reciprocal transplantation experiments [28]. In our study, we have grown plants in single conditions to obtain seed stock that were tested in variable soil environments. Because maternal effects are an important source of intraspecific trait variation [1], we used fully mature dry seeds obtained from glasshouse grown plants during three seasons to minimalize the influence of maternal environment. The comparison between seed response in soil vs. laboratory testing (under saturated water and selected temperature regimes) [30,33] was used in order to see how similar/different they are. While in laboratory conditions we are able to test only the effect of temperature while humidity was kept constant in nature there are much more complex conditions (including soil chemistry and microbiology) [3,33].

In contrast to more stressed conditions of SPN and GRC common garden sites, seeds of both barrel medic and wild pea buried in less stressed conditions of HUN site showed a trend of higher PY release (Figure 3), thus associated with conditions of higher humidity and lower temperature at the HUN site (Figure 4). High diurnal and seasonal temperature fluctuations have previously been shown to release seeds of some species from physical dormancy [2], including laboratory experiments with wild pea [30] and barrel medic [33] with unlimited water availability. The current study, however, demonstrates that humidity plays an important role in the dormancy release in natural soil conditions. However, it is possible that this relates to the association between more humid and less fluctuating temperature environments with lower summer temperatures. In the Liu et al.s study it was found that seed hydration is the main factor for breaking seed dormancy [39].

Seed dormancy release in both species varied among accessions and this could potentially act as a mechanism that favors the persistence of the seed in the soil and helps to distribute genetic diversity through time [35,40,41]. In wild pea, three accessions (IG52518, IG52520, IG52442) with the least PY dormancy after exhumation might be genetically closest to the cultivated pea or even represent some escapes from early pea cultivation (Figure 2) [31,42] and the results agree with Hradilová et al. [30]. However, it seems that the instantaneous soil conditions (water availability) to a greater extent influence the PY dormancy release in both species, whereas arid soil conditions reduce the potential for germination. 
If germination-triggering precipitation events are accompanied by prolonged droughts during the autumn-winter period, the risks and consequences of failed seedling emergence increase [1]. Hence, the investment in PY is a strategy to ensure persistence. The PY was higher in arid than humid soil conditions ( 81 vs. $38 \% ; p<0.001$ ), but was variable between species depending on soil moisture conditions and water availability in the laboratory (Figure 3). Under arid conditions (arid soil and immediately exhumed), the seed dormancy (PY) was higher in wild pea than in barrel medic (96 vs. $68 \%, p<0.001$ ), but under the moist conditions (humid soil plus water-saturated in the laboratory) the seed dormancy was higher in barrel medic than wild pea (20 vs. $8 \%, p<0.01)$.

\subsection{Plasticity and Bet-Hedging Strategy}

Phenotypic plasticity and bet-hedging within and among-season could enhance fitness under environmental variation. The relationship between these two modes of response could be a strategy that buffers species against the unpredictability of a local environment. Seed dormancy release is ideally suited to the study of such relationship because it exhibits plasticity in relation to environmental factors (light, temperature, water, etc.), variance in the potential germination within-season (within-season bet-hedging) and different levels of seed dormancy among growing seasons (among-season bet-hedging) [8].

Our study analyzed the behavior of dormancy release under natural soil conditions for two model legume species, for which physical dormancy is the most important regulator of seedling emergence timing $[30,33]$. The results of our study support the hypothesis that PY release is associated with environmental factors at their site of origin (macroclimatic). A higher proportion of seeds with PY is expected at sites with lower and less predictable precipitation $[7,35]$, and this was indeed observed in wild pea (Table S8), but not in barrel medic (Table S7). However, in agreement with the results $[43,44]$, these differences in PY release in relation to precipitation were less marked than might be expected in view of the substantial precipitation differences among sites of accession origin (Figure 2). These relationships were similar to those found in previous studies under laboratory testing conditions and indicated that those differences are genetically determined [30,33]. The current study found that in addition to large scale (BIOs) environmental factors, there are a number of environmental variables that could represent intense selective pressures at the local scale that have not been considered [45-47]. Genome-environment association studies [33,47-49] showed the evidence of adaptation of in M. truncatula to climate. As already mentioned in our previous study [33], the analysis is likely impacted by several factors inherent to studied sets. At first, there is imprecision in the GPS localization of the origin leading do incorrectly extracted environmental factors. Second there is geographical bias either towards the western part of the Mediterranean in the case of Medicago, or the eastern part in the case of Pisum. Finally, the characteristics of WorldClim data (averages in term of time and space) mask the micro-ecological pattern.

When accessions were grouped according to the macroclimatic conditions (clusters), the regressions (norm of reaction) of PY release on local precipitation variables of common gardens were significant in all clusters, except in humid-humid for barrel medic (Figure 7). Despite the fact that both species showed more PY release under more humid conditions, Pisum showed more rapid PY release with increasing humidity than Medicago. Therefore, both species showed plasticity in germination potential, being more strongly pronounced in Pisum. In contrast, Medicago showed no significant difference in PY release between clusters (Figure 8a), while wild pea of the dry-humid cluster had higher PY release (Figure $8 b$ ), this might be due to the higher occurrence of rainfall after the dry summer under natural environmental conditions that encourage more germination. This can be considered a highly adaptive strategy, being the result of strong environmental selection pressure over time. Earlier emergence can profit from a long growing season and provide a competitive and reproductive advantage for limited resources [50].

We evaluated the plasticity through reaction norms methodology [10] and the bet-hedging within and among seasons with the variance on dormancy release and the level of PY [8]. After seed 
exhumation, mean plasticity on PY was lower in barrel medic compared to wild pea, but barrel medic showed the higher potential of bet-hedging within-season expressed as residual variances of its response in PY release to changes in in-situ precipitation (Figure 7). This intra-cluster variability in barrel medic might reflect a strategy that buffers species against unpredictable local events [36,51,52]. In addition, higher PY dormancy in wild pea can distribute germination across years and acts as a bet-hedging strategy among seasons [52]. The bet-hedging strategies are thus positively associated with more arid and unpredictable habitats and provide the potential to cope with high levels of environmental heterogeneity [34].

Barrel medic had less plastic response than wild pea, which in part could be attributed to high reproductive efficiency that ensures offspring production despite limitations to plant size [53], with high fecundity to spread the risk of failure [43]. In addition, species that frequently and reliably produce seed can afford riskier germination under unfavorable conditions [54]. Under this context, the bet-hedging within-season seems to be a highly efficient mechanism that favors persistence and adaptation to different environments. In seeds, dormancy is a key mechanism for drought avoidance enabling seeds to minimize the risk of drought exposure, yet studies rarely integrate dormancy with vegetative and reproductive strategies [1] and must be more fully integrated into our understanding of dormancy expression.

\section{Conclusions}

The PY dormancy release strategy was different between two studied legume species. In natural soil conditions, wild pea showed higher phenotypic plasticity than barrel medic, while the latter had higher bet-hedging within-season. When the soil conditions were arid, both species showed bet-hedging among-season through PY. On the contrary, higher water availability increased dormancy release, although wild pea showed lower bet-hedging among-season (PY $<10 \%$ ) compared to barrel medic, which was more conservative (PY $\approx 20 \%$ ). These findings suggest that plasticity and bet-hedging should be explored as an important component of dormancy release, but other strategies that occur in different life stages should be integrated into this type of study.

Supplementary Materials: The following are available online at http:/www.mdpi.com/2073-4395/10/7/1026/s1, Table S1: Bioclimatic (WorldClim) long term characteristics of the seed burial side and Meteorological records of the seed burial trial, Table S2: List of tested Medicago accessions with calculated seed dormancy traits and extracted environmental variables, Table S3: List of tested Pisum sativum subsp. elatius accessions with calculated seed dormancy traits and extracted environmental variables, Table S4: Pearson coefficients between bioclimatic variables, Table S5: Correlation between laboratory testing in barrel medic and PY dormant release seeds after soil exhumation, Table S6: Correlation between laboratory testing in wild pea and PY dormant seeds release after soil exhumation, Table S7: Correlation ( $r$ ) between environmental variables of origin for all accessions of M. truncatula and PY dormant seeds release after soil exhumation and correlation (r) between environmental variables of origin for all accessions of $M$. truncatula and PY dormant seeds release after soil exhumation plus seed testing under controlled condition, Table S8: Correlation $(r)$ between environmental variables of origin for all accessions in wild pea and PY dormant seeds release after soil exhumation plus seed testing under controlled condition. Figure S1: Accumulated precipitation $(\mathrm{mm})$ and degrees day $\left({ }^{\circ} \mathrm{Cd}\right)$ in soil seeds burial localities and years, Figure S2: Relationship between the proportion of physically (PY) dormant seeds seed release (imbibed plus germinated) after soil exhumation and after laboratory testing condition $\left(25 / 15^{\circ} \mathrm{C} 21\right.$ days) (soil + testing) in M. truncatula (a) and Pisum satioum subsp. elatius accessions (b).

Author Contributions: Data curation, J.P.R., J.B. and P.S.; formal analysis, J.P.R., J.B., S.P., M.D. and P.S.; funding acquisition, P.S.; investigation, J.P.R., J.B., L.E. and M.D.; methodology, P.S.; project administration, P.S.; writing—original draft, J.P.R., J.B., S.P., M.D. and P.S.; writing-review and editing, J.P.R., J.B., S.P., L.E., M.D. and P.S. All authors have read and agreed to the published version of the manuscript.

Funding: This research was funded by the Grant Agency of the Czech Republic [grant number 16-21053S] and Palacký University grant Agency [IGA-2019_004, IGA-2020_003].

Acknowledgments: We wish to thank to J. Balarynová, I. Hradilová and M. Hýbl for help with seed cleaning and testing. The soil deposition at the testing site by J. Rubia (Spain) is greatly acknowledged.

Conflicts of Interest: The authors declare no conflict of interest. The funders had no role in the design of the study; in the collection, analyses, or interpretation of data; in the writing of the manuscript, or in the decision to publish the results. 


\section{References}

1. Larson, J.E.; Anacker, B.L.; Wanous, S.; Funk, J.L. Ecological strategies begin at germination: Traits, plasticity, and survival in the first four days of plant life. Funct. Ecol. 2020. [CrossRef]

2. Baskin, J.M.; Baskin, C.C. Seeds: Ecology, Biogeography and Evolution of Dormancy and Germination, 2nd ed.; Elsevier, Academic Press: Amsterdam, The Netherlands, 2014.

3. Finch-Savage, W.E.; Footitt, S. Seed dormancy cycling and the regulation of dormancy mechanisms to time germination in variable field environments. J. Exp. Bot. 2017, 68, 843-856. [CrossRef] [PubMed]

4. Bentsink, L.; Jowett, J.; Hanhart, C.J.; Koornneef, M. Cloning of DOG1, a quantitative trait locus controlling seed dormancy in Arabidopsis. Proc. Natl. Acad. Sci. USA 2006, 103, 17042-17047. [CrossRef] [PubMed]

5. Vidigal, D.S.; Marques, A.C.; Willems, L.A.; Buijs, G.; Méndez-Vigo, B.; Hilhorst, H.W.; Bentsink, L.; Picó, F.X.; Alonso-Blanco, C. Altitudinal and climatic associations of seed dormancy and flowering traits evidence adaptation of annual life cycle timing in Arabidopsis thaliana. Plant Cell Environ. 2016, 39, 1737-1748. [CrossRef]

6. Smýkal, P.; Vernoud, V.; Blair, M.W.; Soukup, A.; Thompson, R.D. The role of the testa during development and in establishment of dormancy of the legume seed. Front. Plant Sci. 2014, 5, 351.

7. Willis, C.G.; Baskin, C.C.; Baskin, J.M.; Auld, J.R.; Venable, D.L.; Cavender-Bares, J.; Donohue, K.; de Casas, R.R.; NESCent Germination Working Group. The evolution of seed dormancy: Environmental cues, evolutionary hubs, and diversification of the seed plants. New Phytol. 2014, 203, 300-309. [CrossRef] [PubMed]

8. Simons, A.M. Playing smart vs. playing safe: The joint expression of phenotypic plasticity and potential bet hedging across and within thermal environments. J. Evol. Biol. 2014, 27, 1047-1056. [CrossRef] [PubMed]

9. Sultan, S.E. Phenotypic plasticity for plant development, function and life history. Trends Plant Sci. 2000, 5, 537-542. [CrossRef]

10. Pigliucci, M. Evolution of phenotypic plasticity: Where are we going now? Trends Ecol. Evol. 2005, 20, 481-486. [CrossRef]

11. Cohen, D. Optimizing reproduction in a randomly varying environment. J. Theor. Biol. 1966, 352, 119-129. [CrossRef]

12. Kelly, M. Adaptation to climate change through genetic accommodation and assimilation of plastic phenotypes. Philos. Trans. R. Soc. B 2019, 374, 20180176. [CrossRef]

13. Nicotra, A.B.; Atkin, O.K.; Bonser, S.P.; Davidson, A.M.; Finnegan, J.; Mathesius, U.; Poot, P.; Purugganan, M.D.; Valladares, F.; van Kleunen, M. Plant phenotypic plasticity in a changing climate. Trends Plant Sci. 2010, 15, 684-692. [CrossRef] [PubMed]

14. Via, S.; Lande, R. Genotype-environment interaction and the evolution of phenotypic plasticity. Evolution 1985, 39, 505-522. [CrossRef] [PubMed]

15. Slatkin, M. Hedging one's evolutionary bets. Nature 1974, 250, 704-705. [CrossRef]

16. Starrfelt, J.; Kokko, H. Bet-hedging-A triple trade-off between means, variances and correlations. Biol. Rev. 2012, 87, 742-755. [CrossRef]

17. Donaldson-Matasci, M.C.; Bergstrom, C.T.; Lachmann, M. When unreliable cues are good enough. Am. Nat. 2013, 182, 313-327. [CrossRef]

18. Donohue, K. Niche construction through phenological plasticity: Life history dynamics and ecological consequences. New Phytol. 2005, 166, 83-92. [CrossRef]

19. Van Assche, J.A.; Debucquoy, K.L.A.; Rommens, W.A.F. Seasonal cycles in the germination capacity of buried seeds of some Leguminosae (Fabaceae). New Phytol. 2003, 158, 315-323. [CrossRef]

20. Quinlivan, B.J. The effect of constant and fluctuating temperatures on the permeability of the hard seeds of some legume species. Aust. J. Agric. Res. 1961, 12, 1009-1022. [CrossRef]

21. Quinlivan, B.J. The relationship between temperature fluctuations and the softening of hard seeds of some legume species. Aust. J. Agric. Res. 1966, 17, 625-631. [CrossRef]

22. Quinlivan, B.J. Environmental variation in the long term pattern of germination from hard seeds of Lupinus varius. Aust. J. Exp. Agric. Anim. Husb. 1967, 7, 263-265. [CrossRef]

23. Quinlivan, B.J.; Millington, A.J. The effect of a Mediterranean summer environment on the permeability of hard seeds of subterranean clover. Aust. J. Agric. Res. 1962, 13, 377-387. [CrossRef] 
24. Taylor, G.B. Hardseededness in Mediterranean annual pasture legumes in Australia: A review. Aust. J. Agric. Res. 2005, 56, 645-661. [CrossRef]

25. Bewley, J.D.; Bradford, K.J.; Hilhorst, H.W.M.; Nonogaki, H. Seeds: Physiology of Development, Germination and Dormancy; Springer: New York, NY, USA, 2013.

26. Probert, R. The role of temperature in the regulation of seed dormancy and germination. In Seeds: The Ecology of Regeneration in Plant Communities; Fenner, M., Ed.; CAB International: Wallingford, UK, 2000; pp. 261-292.

27. de Casas, R.R.; Willis, C.G.; Pearse, W.D.; Baskin, C.C.; Baskin, J.M.; Cavender-Bares, J. Global biogeography of seed dormancy is determined by seasonality and seed size: A case study in the legumes. New Phytol. 2017, 214, 1527-1536. [CrossRef] [PubMed]

28. Donohue, K.; de Casas, R.R.; Burghardt, L.; Kovach, K.; Willis, C.G. Germination, post-germination adaptation, and species ecological ranges. Ann. Rev. Ecol. Evol. Syst. 2010, 41, 293-319. [CrossRef]

29. Thompson, J.D. Plant Evolution in the Mediterranean; Oxford University Press: Oxford, UK, 2005.

30. Hradilová, I.; Duchoslav, M.; Brus, J.; Pechanec, V.; Hýbl, M.; Kopecký, P.; Smržová, L.; Štefelová, N.; Vaclávek, T.; Bariotakis, M.; et al. Variation in wild pea (Pisum sativum subsp. elatius) seed dormancy and its relationship to the environment and seed coat traits. PeerJ 2019, 7, e6263.

31. Smýkal, P.; Hradilová, I.; Trněný, O.; Brus, J.; Rathore, A.; Bariotakis, M.; Das, R.R.; Bhattacharyya, D.; Richards, C.; Coyne, C.J.; et al. Genomic diversity and macroecology of the crop wild relatives of domesticated pea. Sci. Rep. 2017, 7, 17384. [CrossRef]

32. Smýkal, P.; Trněný, O.; Brus, J.; Hanáček, P.; Rathore, A.; Roma, R.D.; Pechanec, V.; Duchoslav, M.; Bhattacharyya, D.; Bariotakis, M.; et al. Genetic structure of wild pea (Pisum sativum subsp. elatius) populations in the northern part of the Fertile Crescent reflects moderate cross-pollination and strong effect of geographic but not environmental distance. PLOS ONE 2018, 13, e0194056.

33. Renzi, J.P.; Duchoslav, M.; Brus, J.; Hradilová, I.; Pechanec, V.; Václavek, T.; Machalová, J.; Hron, K.; Verdier, J.; Smýkal, P. Physical dormancy release in Medicago truncatula seeds is related to environmental variations. Plants 2020, 9, 503. [CrossRef] [PubMed]

34. Cochrane, A. Multi-year sampling provides insight into the bet-hedging capacity of the soil-stored seed reserve of a threatened Acacia species from Western Australia. Plant Ecol. 2019, 220, 241-253. [CrossRef]

35. Hudson, A.R.; Ayre, D.J.; Ooi, M.K.J. Physical dormancy in a changing climate. Seed Sci. Res. 2015, 25, 66-81. [CrossRef]

36. Fick, S.E.; Hijmans, R.J. WorldClim 2: New 1-km spatial resolution climate surfaces for global land areas. Int. J. Climatol. 2017, 37, 4302-4315. [CrossRef]

37. Di Rienzo, J.; Casanoves, F.; Balzarini, M.G.; Gonzalez, L.; Tablada, M.; Robledo, C. Infostat Versión 2013; Grupo InfoStat, FCA, Universidad Nacional de Córdoba: Córdoba, Argentina, 2013.

38. Valladares, F.; Sanchez-Gomez, D.; Zavala, M.A. Quantitative estimation of phenotypic plasticity: Bridging the gap between the evolutionary concept and its ecological applications. J. Ecol. 2006, 94, 1103-1116. [CrossRef]

39. Liu, K.; Baskin, J.M.; Baskin, C.C.; Bu, H.; Liu, M.; Liu, W.; Du, G. Effect of storage conditions on germination of seeds of 489 species from high elevation grasslands of the eastern Tibet Plateau and some implications for climate change. Am. J. Bot. 2011, 98, 12-19. [CrossRef]

40. Hu, X.W.; Wu, Y.P.; Wang, Y.R. Different requirements for physical dormancy release in two populations of Sophora alopecuroides relation to burial depth. Ecol. Res. 2009, 24, 1051-1056. [CrossRef]

41. Long, R.L.; Gorecki, M.J.; Renton, M.; Scott, J.K.; Colville, L.; Goggin, D.E.; Commander, L.E.; Westcott, D.A.; Cherry, H.; Finch-Savage, W.E. The ecophysiology of seed persistence: A mechanistic view of the journey to germination or demise. Biol. Rev. Camb. Philos. Soc. 2015, 90, 31-59. [CrossRef]

42. Trněný, O.; Brus, J.; Hradilová, I.; Rathore, A.; Das, R.R.; Kopecký, P.; Coyne, C.J.; Reeves, P.; Richards, C.; Smýkal, P. Molecular evidence for two domestication events in the pea crop. Genes 2018, 9, 535. [CrossRef]

43. Norman, H.C.; Cocks, P.C.; Galwey, N.W. Hardseededness in annual clovers: Variation between populations from wet and dry environments. Aust. J. Agric. Sci. 2002, 53, 821-829. [CrossRef]

44. Ferreras, A.E.; Marcora, P.I.; Venier, M.P.; Funes, G. Different strategies for breaking physical seed dormancy in field conditions in two fruit morphs of Vachellia caven (Fabaceae). Seed Sci. Res. 2018, 28, 8-15. [CrossRef]

45. Guerrero, J.; Andrello, M.; Burgarella, C.; Manel, S. Soil environment is a key driver of adaptation in Medicago truncatula: New insights from landscape genomics. New Phytol. 2018, 219, 378-390. [CrossRef] 
46. Friedman, J.; Middleton, T.E.; Rubin, M.J. Environmental heterogeneity generates intrapopulation variation in life-history traits in an annual plant. New Phytol. 2019, 224, 1171-1183. [CrossRef] [PubMed]

47. Matesanz, S.; Ramos-Muñoz, M.; Moncalvillo, B.; Rubio Teso, M.L.; de Dionisio, S.L.G.; Romero, J.; Iriondo, J.M. Plasticity to drought and ecotypic differentiation in populations of a crop wild relative. $A o B$ Plants 2020. [CrossRef] [PubMed]

48. Yoder, J.B.; Stanton-Geddes, J.; Zhou, P.; Briskine, R.; Young, N.D.; Tiffin, P. Genomic signature of adaptation to climate in Medicago truncatula. Genetics 2014, 196, 1263-1275. [CrossRef] [PubMed]

49. Burgarella, C.; Chantret, N.; Gay, L.; Prosperi, J.-M.; Bonhomme, M.; Tiffin, P.; Young, N.D.; Ronfort, J. Adaptation to climate through flowering phenology: A case study in Medicago truncatula. Mol. Ecol. 2016, 25, 3397-3415. [CrossRef] [PubMed]

50. ten Brink, H.; Gremer, J.R.; Kokko, H. Optimal germination timing in unpredictable environments: The importance of dormancy for both among- and within-season variation. Ecol. Lett. 2020, 23, 620-630. [CrossRef] [PubMed]

51. Liyanage, G.S.; Ooi, M.K.J. Intra-population level variation in thresholds for physical dormancy-breaking temperature. Ann. Bot. 2015, 116, 123-131. [CrossRef]

52. Burghardt, L.T.; Metcalf, C.J.E.; Donohue, K. A cline in seed dormancy helps conserve the environment experienced during reproduction across the range of Arabidopsis thaliana. Am. J. Bot. 2016, 103, 47-59. [CrossRef]

53. Bonser, S. High reproductive efficiency as an adaptive strategy in competitive environments. Funct. Ecol. 2013, 27, 876-885. [CrossRef]

54. Duncan, C.; Schultz, N.L.; Good, M.K.; Lewandrowski, W.; Cook, S. The risk-takers and -avoiders: Germination sensitivity to water stress in an arid zone with unpredictable rainfall. AoB Plants 2019. [CrossRef]

(C) 2020 by the authors. Licensee MDPI, Basel, Switzerland. This article is an open access article distributed under the terms and conditions of the Creative Commons Attribution (CC BY) license (http://creativecommons.org/licenses/by/4.0/). 